\title{
A PAIXÃO PELO AUTÔMATO: A CONDIÇÃO MAQUÍNICA
}

THE PASSION TOWARDS THE AUTOMATON: THE MACHINIC CONDITION

LA PASIÓN POR EL AUTÓMATA: LA CONDICIÓN MAQUÍNICA

\author{
Gustavo Caetano de Mattos Mano* \\ Amadeu de Oliveira Weinmann ${ }^{* *}$ \\ Roberto Henrique Amorim de Medeiros ${ }^{* * *}$
}

\begin{abstract}
RESUMO
Neste escrito, visamos a explorar os desdobramentos da figura do autômato no cinema e o fascínio que ele desperta. Sob a forma de ensaio, traçamos a genealogia do autômato na cultura, da Grécia antiga a Hollywood, e examinamos sua apariçãao ao longo da história do cinema, assinalando alguns dos filmes em que suas diversas facetas encontram-se representadas. Do precipitado formado pela incidência fílmica do autômato, sublinhamos os traços conferidos na Contemporaneidade a essa composição, acentuando a filiação ao homem, a natureza robótica e a obediência ao desígnio. Dialogando com a psicanálise, examinamos o conceito de duplo e de compulsão à repetição, assinalando a figura do autômato como duplo do sujeito da Contemporaneidade, encarnando a fantasia de denegação do mal-estar produzida como legado do tecnicismo, do cientificismo e do capitalismo tardio. Concluímos que os autômatos do cinema desvelam uma verdade sob o caráter de ficção: os sujeitos da Contemporaneidade fantasiam os ideais da condição maquínica.
\end{abstract}

Palavras-chave: Cinema. Autômato. Contemporaneidade. Psicanálise.

\begin{abstract}
In this article we intend to explore the displays of automaton figure on movies and the passion it arouses. Written in the form of an essay, this paper traces the automaton genealogy inside our culture, from Ancient Greece to Hollywood, and his presence in cinema history, pointing out some of the movies where its multiple appearances are represented. We have highlighted from the automaton occurrence on movies, the traces checked
\end{abstract}

Texto recebido em 18 de março de 2015 e aprovado para publicação em 13 de maio de 2016.

"Mestre em Psicologia Social e Institucional pela Universidade Federal do Rio Grande do Sul (UFRGS), psicólogo. Endereço: Avenida Coronel Lucas de Oliveira, 2241, apto. 201 - Bairro Petrópolis, Porto Alegre-RS, Brasil. CEP: 90460-001. Telefone: (51) 9136-6584.E-mail: gustavo.mano@gmail.com.

**Professor doutor no Departamento de Psicanálise e Psicopatologia do Instituto de Psicologia da UFRGS, professor do Programa de Pós-Graduação em Psicanálise: Clínica e Cultura da UFRGS. Endereço: Avenida Montenegro, 186, apto. 602, Bairro Petrópolis, Porto Alegre-RS, Brasil. CEP: 90460-160. Telefone: (51) 9184-3581. E-mail: weinmann.amadeu@gmail.com.

***Professor doutor no Bacharelado e Pós-Graduação em Saúde Coletiva da UFRGS. Endereço: Rua São Manoel, 963, Bairro Rio Branco, Porto Alegre-RS, Brasil. CEP 90620-110. Telefone: (51) 3308-5233. E-mail: robertoamorim80@hotmail.com. 
at contemporary times in this composition, underlining the filiation to mankind, the robotic nature and the submission to fate. Keeping a dialogue with psychoanalytical theory, the authors explore the concepts of the double and the repetition compulsion, marking the automaton figure as a double of the contemporary subject, embodying the fantasy of denying the uneasiness produced as a legacy of technicality, scientism and late capitalism. Our conclusion is that the movies automata unveil the truth hiding under the status of fiction: contemporary subjects fantasize the ideals of machinic condition.

Keywords: Cinema. Automaton. Contemporary. Psychoanalysis.

\section{RESUMEN}

En este escrito nos proponemos estudiar, con la ayuda del psicoanálisis, los desdoblamientos de la figura del autómata en el cine y la fascinación que provoca. En forma de ensayo, rastreamos la genealogía del autómata en la cultura, desde la antigua Grecia a Hollywood, y su aparición en la historia del cine, enumerando algunas de las películas en las que sus diversas facetas son representadas. De la observación de la incidencia del autómata en películas, se destacan los rasgos que hoy en día son conferidos para esta composición, subrayando la filiación al hombre, la naturaleza robótica y la obediencia a su destino. Dialogando con el psicoanálisis, examinamos los conceptos de doble y de compulsión de repetición, teniendo en cuenta el autómata como el doble del sujeto de la actualidad, que incorpora la fantasía de negación del malestar producida como un legado del tecnicismo, del cientificismo y del capitalismo tardío. Llegamos a la conclusión de que los autómatas del cine dieron a conocer una verdad bajo el status de ficción: los sujetos contemporáneos fantasean con los ideales de la condición maquínica.

Palabras clave: Cine. Autómata. Contemporáneo. Psicoanálisis.

\section{INTRODUÇÃO}

civilização sempre encontrou formas criativas de representar as interrogações
humanas. Mitos, fábulas e os gêneros de ficção prestam-se particularmente
bem a esse propósito: além de oferecerem um manancial virtualmente
infinito de possibilidades, tão extensa quanto for a imaginação dos autores, as
narrativas fantásticas, gozando do salvo-conduto da irrealidade, permitem a
suspensão momentânea das amarras da censura e a abordagem de temas que,
doutra forma, talvez fossem insuportáveis. Assim, a ficção, à semelhança das
montagens oníricas, cumpre a função de oferecer vias de enunciação para as mais
caras questões dos homens. 
Como ressalta Mattuella (2012, p. 267), as produções culturais “interpretam o recalcado de certa configuração social, explicitando através de uma forma mais ou menos metafórica os pontos de silêncio que dão coesão ao tecido simbólico de uma determinada época”. Nessa tarefa interpretativa, o cinema surge como um poderoso agonista: mais do que um mero veículo para as narrativas, a sétima arte constitui uma linguagem singular, estruturada com base em leis próprias e ordenamentos específicos, que dialoga com a cultura e oferece imagens que oxigenarão as leituras sobre os sujeitos que nela habitam.

Neste escrito, derivado de discussões estabelecidas a partir de uma atividade de extensão sediada na Universidade Federal do Rio Grande do Sul, visamos a explorar, com o auxílio da psicanálise, os desdobramentos da figura do autômato no cinema e do fascínio que ele desperta. Adotamos, pois, o ensaio como forma. A escolha metodológica se dá por compreendermos ser essa a via em que mais fielmente se contemplam não apenas as questões que moveram a investigação, mas o próprio decurso da pesquisa, sem a pretensão de uma construção fechada, como assinala Goethe (2003). Neste trabalho, traçaremos, em um primeiro momento, a genealogia do autômato na cultura; então avançaremos, apontando os traços conferidos pelo cinema a essa composição; a seguir, pontuaremos a função de duplo frente ao sujeito da Contemporaneidade e, ao final, discutiremos as marcas do automatismo no cinema atual.

\section{BREVE GENEALOGIA DO AUTÔMATO}

O termo autômato provém da latinização do grego aủtó $\alpha \alpha \tau o v$ (ou também $\alpha \cup \tau о \mu \alpha \tau \omega \nu$ e $\alpha \cup \tau о \mu \alpha \tau \varsigma \varsigma)$ e traduz-se por "movido por vontade própria" ou "aquele que se move por si próprio". Nas histórias de Homero, os automatones designavam seres artificiais de formas humanoides, zoomórficas ou monstruosas forjadas por Hefesto, constando dentre eles tripés dourados que realizam o translado do Olimpo e Talos, o gigante de bronze. ${ }^{1}$ Algumas vertentes da literatura helênica atribuem também a Dédalo a confecção de criaturas semelhantes, animadas pelas misteriosas propriedades do mercúrio. ${ }^{2}$ A literatura medieval, como demonstra Bruce (1913), apresenta diversas passagens em que autômatos ganham a cena; muitas delas como remodelagens de narrativas consagradas, eventualmente mescladas a elementos da tradição ocidental. Seres de natureza similar habitariam posteriormente as fábulas de Hans Christian Andersen

1 O filme Jasão e o velo de ouro, de 1963, visita essa tradição, apresentando o confronto entre o autômato e os argonautas; já Bruce (1913) situa como um presente de Zeus a Europa, derradeiro representante dos homens da Era de Bronze; e, nesse caso, não seria fruto do trabalho de um artesão ou feiticeiro, mas o último sobrevivente de uma raça extinta.

2 Em um comentário sobre a investigação de Bruce, Hyde (1913) propõe uma interpretação diferente do mito de Dédalo, apoiado em uma passagem de Diodoro Sículo. Nela, Dédalo seria um artífice tão superior aos demais que, em comparação, suas produções pareciam dotadas de vida. Isso se deveria ao fato de que suas figuras eram construídas com braços descolados do corpo, pernas afastadas e olhos abertos (representando com maior realismo a noção de movimento). Para Hyde, o mito de Dédalo encarna um momento de passagem na técnica artística, representando a ruptura com modelos anteriores. 
e os contos de E. T. A. Hoffmann; as epopeias pré-modernas e os filmes de Hollywood; os sonhos dos homens e as formações da cultura.

Tecnicamente, qualquer ente dotado de capacidade de ação independente poderia ser considerado um autômato. A amplitude do conceito, quando observado somente o caráter terminológico, não estabeleceria distinção entre uma esteira de linha de montagem, um manequim semovente, um videocassete programável e um androide assassino; para este trabalho, ainda que a pluralidade de representações nos interesse, faremos um necessário recorte operacional. $\mathrm{O}$ próprio termo autômato carrega consigo um oximoro de difícil resolução: supõe uma força independente, uma energia espontânea, elementos que a realidade desconhece. Como poderíamos crer que algo extraia sua força motriz de si mesmo sem afrontar diretamente os mais basais princípios de física? Se houvéssemos de buscar, a título de explicação ao moto, uma causalidade e uma anterioridade, invalidaríamos imediatamente a possibilidade do auto. Descartamos, portanto, a viabilidade lógica do automatismo absoluto e assumimos, como recorte operacional, o autômato como criação que, em maior ou menor escala, pode prescindir da mediação humana para operar.

Tomaremos ainda, como eixo da análise, os autômatos que, nas produções fílmicas, tocam o tecido da cultura através do conceito de estranho, ao qual nos debruçaremos no decorrer da discussão. Além disso, não faremos, em um primeiro momento, discriminação entre autômatos maquínicos (pertencentes à tradição dos mekhanaí, lembrados por Nuñez, 2008), autômatos místicos (entre os quais se sobressai o golem lembrado pela poesia de Borges, 1974), autômatos extraterrestres (como Gort de $O$ dia em que a terra parou), e autômatos orgânicos (classe consagrada no monstro de Frankenstein). Nossa investigação buscará preservar a polissemia da condição do autômato para poder encontrar, nos traços deixados pelo autônomo no cinema, os pontos de condensação que fazem dele um interrogante da cultura.

\section{OS AUTÔMATOS E O CINEMA}

Determinar a estreia dos autômatos na grande tela é uma tarefa espinhosa. Metrópolis, de 1927 (Lang, 1927), desponta como marco ao apresentar a androide Maria, prefigurando o modelo do autômato robótico. Antes disso, contudo, o diretor alemão Ernst Lubitsch apresentara, na comédia Die Puppe, de 1919 (Davidson, 1919), uma encantadora boneca mecânica cujas feiçôes replicavam a filha do construtor (e a alusão ao conto O Homem de Areia, de E. T. A. Hoffmann, não parece ser acidental). ${ }^{3}$ Ainda anterior é a produção Der Golem, ${ }^{4}$ de 1915 ,

\footnotetext{
3 Em uma espécie de subversão incomum dos enredos envolvendo autômatos, em Die Puppe é a humana (a filha do artífice) quem se disfarçara de boneca.

4 Sendo as versões brasileiras inexistentes, cabe-nos oferecer soluções para os títulos mencionados. Die Puppe pode ser lido como $A$
} 
dirigido por Wegener e Galeen (1915), primeiro filme de uma trilogia que conta ainda com Der Golemund die Tänzerin (1917) e Der Golem, wieer in die Weltkam (1920), a qual revisita a criatura de barro fundada no folclore judaico. Além disso, o Edison Studios realizou, em 1910, Frankenstein, dirigido por Dawley (1910), adaptação em curta-metragem do célebre romance de Mary Shelley. Para Bueno e Martins (2012), o ingresso do autômato no cinema mereceria ser creditada a Georges Méliès e a um filme perdido chamado Poupée Vivante, que teria sido rodado em 1908; uma investigação mais profunda descobriria que o mesmo autor realizou, em 1897, o curta Gugusse et l'Automate (Méliès, 1897); e talvez aqui tenhamos resgatado, efetivamente, a primeira apresentação do autômato na grande tela. ${ }^{5}$

Após Metrópolis (Lang, 1927), outros autômatos receberiam destaque no cinema: o Espantalho de $O$ Mágico de Oz, ${ }^{6}$ de 1939 (LeRoy, 1939), Gort de O dia em que a Terra parou, de 1951 (Blaustein \& Wise, 1951), e Robby, de Planeta proibido, de 1956 (Nayfack \& Wilcox, 1956). A multiplicidade de formas assumida pelo autômato nas produçôes fílmicas se mantém durante a primeira metade do século XX.

A partir de 1960, todavia, testemunhamos uma guinada crucial na composição cinematográfica do autômato, impulsionada em grande parte pela evolução dos efeitos especiais e pela consolidação do gênero da ficção científica. Ao contrário da literatura e do rádio (onde frequentemente o manejo hábil da palavra basta para sustentar a condução da narrativa), no cinema, as possibilidades de narratividade não prescindem do alcance dos recursos visuais disponíveis, incluindo nessa categoria elementos tão heterogêneos quanto maquiagem, cenários, animatrônicos, efeitos de edição e computação gráfica. Embora a ficção de um modo geral goze, em relação à audiência, da prévia suspensão de descrença, alguns de seus ramos (e a ficção científica em particular) não podem prescindir de certa aparência de veracidade, o que, até a metade do século XX, tendo em vista as severas limitações das tecnologias cinematográficas, nem sempre era possível alcançar.

O desenvolvimento de técnicas mais apuradas de efeitos especiais pavimentou o caminho para que a ficção científica pudesse firmar-se na telona não apenas como um ramo experimental ou cômico, mas como um gênero cinematográfico

Boneca, assim como Poupée Vivante permite a conversão para Boneca viva. Já na trilogia de Paul Wegener e Henrik Galeen, Der Golem poderia ser traduzido por O Golem; Der Golemund die Tänzerin se transformaria em O Golem e o Dançarino e Der Golem, wie er in die Weltkam tornaria-se $O$ Golem, Como ele veio ao mundo. Por fim, Gugusse et l'Automate poderia ser compreendido como $O$ palhaço e o autômato, em tradução livre.

5 Também é digna de nota a peça $R . U . R$., do tcheco Karel apek, encenada pela primeira vez em 1921, que introduz o termo robô na cultura popular, lançando mão de um neologismo derivado da expressão tcheca utilizada para designar trabalhos forçados, corveia ou escravidão.

6 Poderíamos considerar o Homem de Lata também um autômato? Na obra de L. Frank Baum, a origem do Espantalho não deixa muitas dúvidas: trata-se de um boneco de palha confeccionado por fazendeiros com a missão de afugentar corvos. Não sabemos o que o trouxe à vida. O Homem de Lata, por outro lado, nada mais é do que um humano que, gradualmente, substituiu seus membros por partes metálicas após sucessivos acidentes com um machado encantado até que nada mais sobrasse de seu corpo original. Parece, assim, aproximar-se mais da noção de ciborgue do que do conceito de autômato. 
sólido. É nesse campo que Stanley Kubrick realizaria, em 1968, 2001: uma odisseia no espaço, lançando mão dos mais sofisticados recursos técnicos e artísticos disponíveis e elevando o patamar dos efeitos especiais para as produções vindouras. Pouco tempo depois, em 1977, George Lucas e Steven Spielberg apresentariam, respectivamente, Guerra nas estrelas (Kurtz \& Lucas, 1977) e Contatos imediatos de terceiro grau (Phillips, Phillips \& Spielberg, 1977), elevando o patamar dos efeitos especiais e inscrevendo em definitivo a ficção científica na era dos blockbusters.

Ao final do século XX, já é possível perceber os traços conferidos pela escola hollywoodiana à figura do autômato e reforçados nas produçōes dos primeiros anos do século XXI, notando claramente a influência da ficção científica nessa composição. $\mathrm{Na}$ virada do milênio, o autômato converte-se de convidado eventual a participante regular das obras cinematográficas. A Modernidade tardia apaixona-se pela figura do autômato, e o retorno sistemático dessa entidade ao longo da história do cinema (e, em particular, nos últimos 40 anos) produz um precipitado que se oferece à interpretação. Da análise do léxico cinematográfico, recortamos aqueles traços que parecem direcionar a composição contemporânea do autômato no cinema, remetendo, quando parecer apropriado, às películas onde cada argumento encontra expoentes de maior evidência ou subverte a tendência assinalada:

a) O autômato é filho do homem. Ainda que, em algum momento, a capacidade de replicação e reprodução seja alcançada e os autômatos desenvolvam o poder de gerarem descendentes (como ocorre nas séries $O$ exterminador do futuro e Matrix), sem dependerem da ação do homem, no ponto mais distante da árvore genealógica, invariavelmente encontraremos a mão humana. Os autômatos representados no cinema frequentemente são, portanto, descendentes do Homo sapiens (se não em termos biológicos, certamente em termos simbólicos). Em Blade runner, a filiação do replicante Roy é explorada no encontro com Tyrell; em Guerra nas Estrelas - Episódio I: a ameaça fantasma, o jovem Anakin Skywalker constrói o droide C3PO para exercitar sua veia criativa e aplacar sua solidão; motivação não tão distinta daquela encontrada no Dr. Viktor Frankenstein. Por outro lado, os Autobots e Decepticons, da franquia Transformers, constituem exceção a essa regra, mas os seres que essa franquia apresenta parecem estar mais próximos de organismos alienígenas com fisiologia maquínica do que de autômatos propriamente ditos, assim como Christine, o carro demoníaco do filme inspirado na obra de Stephen King, coloca-se mais do lado da possessão sobrenatural do que no campo do automatismo. 
b) O autômato tem natureza predominantemente robótica. Se os autômatos primitivos eram fruto da criatividade divina (como nas máquinas de $\mathrm{He}$ festo) ou da ação sobrenatural (como no caso do golem), os autômatos contemporâneos são, em sua quase totalidade, produto da mais sofisticada tecnologia; ou, melhor dizendo, de uma tecnologia fantástica, que mescla, em maior ou menor grau, fundamentos científicos e virtualidades inverossímeis. Circuitos elétricos aliam-se a cérebros positrônicos, hardwares extraem energia de antimatéria, concessóes imaginativas estabelecem um diálogo fluido com a mecatrônica atual. Paralelamente, é curioso notar que, dentro da pluralidade de gêneros na qual poderíamos encontrar a figura do autômato (abrangendo da narrativa maravilhosa e das fábulas ao realismo fantástico e ao terror), é na ficção científica que ele fincará raízes. As criaturas de Der Golem e A invenção de Hugo Cabret escapam à regra (a primeira por ser de natureza mística; a segunda, puramente mecânica); as de $O$ exterminador do futuro, Matrix, Wall-E e Alien, exclusivamente robóticas, endossam-na.

c) O autômato tem um desígnio. Cada autômato vem ao mundo com uma razão de existência, um objetivo, uma função, um desígnio que lhe antecede. Os propósitos dos autômatos apresentam margem ampla de variação: podemos encontrar robôs de protocolos diplomáticos ou droides de reparos (como C3PO e R2D2 na série Guerra nas estrelas), amantes mecânicos (Gigolo Joe em A.I.: inteligência artificial), máquinas de guerra urbana (ED-209, em RoboCop), avaliadores de vegetação extraterreste (como EVE de $W a l l-E)$ e infinitas outras possibilidades. Frequentemente, esse desígnio costuma aparecer sob a insígnia da programação, que delimita e regula as possibilidades da existência - RoboCop tinha as diretrizes básicas; Sonny, de $E u$, robô, pautava-se (ou deveria pautar-se) pelas três leis da robótica, e assim por diante. Não é incomum, contudo, que o argumento do filme explore precisamente a torção desse desígnio e as consequências decorrentes disso.

O recorte desses traços - a fliação ao homem, a natureza robótica e a obediência ao desígnio - desvela mais do que simples características de uma entidade ficcional emprestada ao universo do cinema: ele sugere a elevação do autômato como espelho das questôes humanas. A gênese do autômato contemporâneo, parodiando os mitos de criação do homem com o sopro divino substituído por um interruptor, aponta para a relação de familiaridade dessa figura fantástica com a humanidade. 
Asimov (2010) observava que os autômatos da ficção científica são representados como seres próximos da perfeição, atendendo às exigências de eficácia, precisão, celeridade e antecipação calculada, enquanto os autômatos do mundo real resumiam-se a pouco mais que braços articulados, sem qualquer semelhança com o ser humano, o que dificultaria visualizar efetivamente os robôs como pseudopessoas. Poderíamos nos perguntar se essa afirmação, datada do longínquo ano de 1983, seguiria válida para o mundo atual, mas a resposta talvez não seja tão importante quanto a constatação de que, no imaginário cultural presente (e, particularmente, no repertório cinematográfico), os autômatos representam o duplo do homem contemporâneo e, especialmente, sua condição maquínica.

\section{O DUPLO E A CONDIÇÃO MAQUÍNICA}

Cunhamos a expressão condição maquínica em alusão à célebre obra de Hannah Arendt, A condição humana. Nesse escrito, Arendt (2007) trabalha com o conceito de condição humana implicado ao social, e, portanto, distinto da noção de natureza humana. Essa perspectiva, como notam Cavarero e Butler (2007), retira a reflexão sobre o humano do campo do universal e do a-histórico para recolocá-la em outros termos: ela não considera somente as condições nas quais a vida foi concedida ao homem, mas especialmente as condições que o próprio homem construiu para viabilizar sua existência. "É por isto que os homens, independentemente do que façam, são sempre seres condicionados", diz-nos Arendt (2007, p. 17). Podemos interpretar o conceito de condição, portanto, como algo que está para além das exigências vitais e universalidades biológicas do Homo sapiens; nas palavras da autora, não apenas a conditio sine qua non, mas a conditio per qua; a condição pela qual os humanos reconhecemse como humanos. E tal reconhecimento, na Contemporaneidade, é atravessado por uma denegação cultural do mal-estar constituinte dos sujeitos, referindo-os a ideais de não castração que espelham, fantasiosamente, a existência maquínica. É nesse jogo de miradas e identificações que, na Contemporaneidade, o autômato desponta como duplo do homem.

A categoria do duplo, introduzida por Freud no texto $O$ estranho, de 1919, assinala um ponto de não reconhecimento do eu na relação com o outro (e, concomitantemente, na relação consigo mesmo). Freud (1919/2006), ${ }^{7}$ que se vale do exemplo de uma experiência própria de estranhamento no espelho de um vagão do trem, deixa transparecer a dimensão do eu em sua instância imaginária; aquilo que não cessa de se inscrever e, nessa condição, deixa margem para que o

\footnotetext{
7 A primeira data indica o ano de publicação original da obra, e a segunda, a edição consultada pelo autor, que só será pontuada na primeira citação da obra no texto. Nas seguintes, será registrada apenas a data de publicação original.
} 
deslizamento da imagem do eu confronte o eu ideal. Lacan (1955-1956/2010, p. 172) nos recorda, no seminário intitulado As psicoses, que o eu nunca está só: "Ele sempre comporta um estranho gêmeo, o eu ideal". E acrescenta: "É nisso que esse personagem que faz eco aos pensamentos do sujeito intervém, o vigia, designa gradativamente a sequência de suas ações, as comanda, não é suficientemente explicado pela teoria do imaginário e do eu especular”. O ensino lacaniano marca-se pelo cuidado terminológico. $\mathrm{O}$ uso do adjetivo estranho, portanto, não pode ser tomado como despropositado; o eu ideal opera como duplo do eu, salientando a condição de parcialidade desse ente. Há, portanto, algo para além do eu que o interroga e que de sua heterogênea montagem participa, ainda que em uma posição de não reconhecimento.

É desde o lugar de duplo do homem que o autômato lançará interrogações sobre a humanidade e a cultura. No cinema, essas questôes aparecem sob facetas variadas. Os autômatos amotinados que se voltam contra seus criadores, exemplificados em Matrix, Eu, robô e X-Men: dias de um futuro esquecido, representam tanto a exploração do homem pelo homem (e o receio de uma futura revanche social) quanto os temores de subversão da tecnologia para fins nefastos, um medo compreensivelmente inflado após a II Guerra Mundial. ${ }^{8}$ Em O homem bicentenário, RoboCop e Blade runner, observamos que a interrogação recai sobre o limite entre o humano e o maquínico. No recente Ela, perguntamonos até que ponto um programa de computador é capaz de suscitar, cultivar e simular as virtudes humanas que consideramos mais preciosas (o amor, a alteridade, o desejo). Ao situar-se como aquele que pode interpelar o sujeito desde uma posição simultaneamente estranha e familiar, o autômato produz o efeito de paixão, desvelando no radical grego pathos tanto a via do fascínio que produz (e, assim, sustenta sua persistência nas produções culturais) quanto a via do sofrimento que desvela (oferecendo, portanto, um espelho cruel sobre a condição humana).

A trilha freudiana oferece luz sobre essa questão por meio do conceito Wiederholungszwang, a compulsão à repetição (ou automatismo de repetição) enunciada em Além do princípio do prazer. Tal formulação é cunhada por Freud para dar conta da repetição, na clínica, de situações em que não há nenhuma possibilidade de extrair satisfação nem em relação ao princípio do prazer nem em relação ao princípio da realidade. Situam-se além desses processos, regidas por uma força outra. Freud (1920/2006, pp. 32-33) caracteriza a compulsão

\footnotetext{
8 Isaac Asimov (2010), que cunha o termo "tecnofobia", recorda que a introdução do automatismo no início da revolução industrial despertou na população aflorações de hostilidade contra as máquinas, movida predominantemente pelo medo de que os postos de trabalho humano fossem substituídos por engrenagens e pistões, gerando multidōes de desempregados. Asimov pondera que a expectativa pessimista não se concretizou: a evolução tecnológica prenunciou um tempo de prosperidade econômica, levando à ampliação do número de vagas de trabalho (eventualmente, na própria operação das máquinas). Todavia não estamos livres do pesadelo tecnofóbico. Como pontua Asimov, "À medida que [o computador] for ficando mais compacto e versátil, mais complexo, capaz e inteligente, será que não poderá substituir, além da pessoa, toda a humanidade?” (p. 13).
} 
à repetição na cena do mundo como uma "perpétua recorrência da mesma coisa", que poderia ser confundida como um "destino maligno"9 ou uma "força demoníaca” responsável por lançar o sujeito em circuitos de reprises tão previsíveis quanto inevitáveis. Não é demasiado lembrar que o conceito de pulsão de morte, força responsável por animar a compulsão à repetição, é extraído da especulação sobre o funcionamento de organismos unicelulares; reduzidos, nesse exame, a protótipos de máquinas vitais.

A pulsão de morte, nos termos em que Freud a concebeu, operaria no sentido de reconduzir o ser vivo a um estado anterior, inerte, quiçá inorgânico: ${ }^{10}$ um estado em que a vida cede lugar ao puro automatismo. Em Mal-estar na civilização, Freud (1930/2006) oferece uma definição eloquente:

A ordem é uma espécie de compulsão a ser repetida, compulsão que, ao se estabelecer um regulamento de uma vez por todas, decide quando, onde e como uma coisa será efetuada, e isso de tal maneira que, em todas as circunstâncias semelhantes, a hesitação e a indecisão nos são poupadas (p. 100).

Nas representações do autômato no cinema, a repetição do desígnio, da programação e das diretrizes predomina sobre o princípio do prazer (do qual, aliás, raramente se tem notícia). Na maioria das vezes, trata-se daquilo que Lacan (1964/2008) identificou como autômaton; o imutável retorno ao signo, que congela o circuito da repetição em uma sistemática reprodução do mesmo. Por sua vez, a tiquê, o encontro com o real, capaz de operar a produção do novo, é de outra ordem: Lacan ressalta que ela se define "por só nos poder vir de um ser capaz de escolha" (Lacan, 1964, p. 73). A ruptura do desígnio e a quebra da programação original aparecem somente no momento de transcendência do autômato, quando ele se encontra no limite de seu ser; ou seja, quando ele é capaz de torcer o regime de signos que a ele se impóe e escolher uma narrativa nova, própria, ainda que ao acaso, ainda que inventada. ${ }^{11}$

O autômato, contudo, não constitui duplo de qualquer homem. Aquilo que compreendemos como o homem não é, em absoluto, uma constante universal; especialmente porque o próprio homem é uma composição circunstancial, produto de tramas peculiares e configurações sócio-históricas complexas. Com seus traços (recordemos: a filiação ao homem, a natureza robótica e a obediência

\footnotetext{
9 Poderíamos equiparar as "neuroses de destino" ao desígnio dos autômatos? Possivelmente.

10 Não é acidental que o fundador da psicanálise tenha definido a regência da pulsão de morte como aquilo que se encontra para além do princípio do prazer justamente no momento em o mundo saía da I Guerra Mundial (e caminhava inapelavelmente para a segunda) e os horrores do front vinham na forma das mais pesadas neuroses traumáticas. Como sublinha Walter Benjamin em Experiência e pobreza (2010) os sujeitos saíram da guerra mais pobres em experiências comunicáveis; um silenciamento emblemático da impossibilidade de transformar em palavras o radical do sofrimento, em ultrapassar o circuito da repetição automática, uma "indisposição subjetiva” sintomática abordada por Freud exatamente em Além do princípio do prazer.

11 Lacan, em O seminário I, é categórico ao reconhecer o ser falante como sujeito. "E por quê?”, pergunta-se Lacan (1953-1954, p. 225). "Por uma simples razão, por que ele é capaz de mentir". A mentira, invenção de uma verdade que se esqueceu de acontecer, evidencia aquilo que a ciência recusa: que aquele que fala encontra-se em uma dimensão distinta daquilo que ele fala; em outras palavras, o mentir coloca a descoberto a divisão fundamental do sujeito.
} 
ao desígnio), o autômato assume a posição de duplo, portanto, em um contexto específico, no bojo do capitalismo tardio e do cientificismo em sua plena potência. Conjugados, o discurso capitalista e o discurso científico favorecem o apagamento da singularidade e das marcas autorais; ou seja, operam a favor do automatismo. Não se trata aqui do automatismo mental utilizado por Clérambault na descrição de quadros psicóticos (Quinet, 2010); referimo-nos, pois, aos automatismos silenciosos da vida cotidiana, às rotinas pré-fabricadas, às práticas recursivas, aos padrões globais, a tudo que contribui para tornar os sujeitos menos sujeitos. Em Monumento a um jovem monólito, Dahmer (2009) descreve a sobrevivência do homem comum diante das exigências do cotidiano:

O trabalho é uma grande cadeia e você sentirá muito alívio por ter uma. A cadeia engrandece o homem, o sangue do dinheiro tem poder. Reze. Reze ajoelhado por uma carreira, dê a sua vida por ela. [...] Nas salas refrigeradas, seus colegas de trabalho fabricam informação e, frios, sonham com o dia dez do próximo mês. Você é o Babaca do Dia Dez, não há como mudar o seu próprio destino. Babaca que acorda assustado, porque ninguém deve atrasar mais de vinte e cinco minutos. Eles descontam em folha e você é refém da folha, do salário, do medo. Ninguém tem o direito de ser feliz, mas você ganhará a sua esmola de seis feriados por ano. E todos nós vamos enfrentar, juntos, um imenso engarrafamento até a praia. Para fingir que ainda estamos vivos. Para mostrar que ainda somos capazes de sentir prazer.

Note-se que a ácida descrição de Dahmer confronta a previsão de Hannah Arendt (2007, p. 12) acerca do "advento da automação, que dentro de algumas décadas provavelmente esvaziará as fábricas e libertará a humanidade do seu fardo mais antigo e mais natural, o fardo do trabalho e da sujeição à necessidade". Poderíamos indagar se a automação logrou êxito quanto à promessa de libertação do fardo do trabalho, como sonhava Arendt, ou se, pelo contrário, ao produzir dispositivos que tornaram prescindível a delimitação de espaços laborais específicos, eliminou também a possibilidade de estabelecer zonas de não trabalho, tornando esse encargo ainda maior.

O discurso capitalista sugere que o sacrifício laboral ofereceria, como retorno, a possibilidade de gozar da pletora de bens de consumo com obsolescência programada disponiveis ao alcance de um clique; recalca-se, sob esse semblante, o fato de que é o próprio sujeito que se consome e se descarta. Freud, herdeiro do racionalismo do século XIX, acreditava que a ciência poderia salvar o homem de sua ignorância e de seu sofrimento. Mas, como se lê em Mal-estar na civilização, essa busca pelo domínio da natureza converteu-o em uma espécie de "Deus de prótese", sem ignorar que "atualmente, o homem não se sente feliz em sua posição de semelhante a Deus" (Freud, 1930, p. 98). A promessa da redenção através da ciência vacila, e Jerusalinsky (2011, p. 236) pontua que "é neste ponto de fracasso que nasce o homem sacrificável, o homem mecânico, de quem não 
se sabe quantos aparatos conectados poderia ter para se continuar a considerálo humano". Essa mecanicidade encontra guarida justamente nos pontos que deveriam oferecer resistência: não faltam modalidades terapêuticas que reduzem a narratividade do sujeito a protocolos binários, entrevistas reiterativas, tabelas, escalas e listas, verbetes de compêndios e entradas de manuais.

O discurso científico contemporâneo fomenta a promessa de que é possível tudo saber e, como efeito, desmentir a cisão do sujeito. Se os autômatos do cinema expressam uma recorrência da natureza robótica, os sujeitos da Contemporaneidade, atravessados pelo capitalismo tardio, fantasiam os ideais da condição maquínica.

\section{INTERROGAÇÔES FINAIS SOBRE O AUTOMATISMO}

Há, porém, outra faceta do automatismo que merece ser pontuada. Mencionamos, na abertura deste ensaio, que a articulação entre o cinema e a ficção era de especial interesse à leitura crítica da cultura graças à inequiparável potência de traduzir em imagens a imaginação. Todavia um olhar cuidadoso para o repertório cinematográfico revelará uma peculiar tendência acentuada a partir dos anos 2000. Tomemos como exemplo o filme RoboCop, que estreou nos cinemas em 1987. Em 1990, foi lançado RoboCop 2, seguido por RoboCop 3, de 1993. Quando o cânone fílmico ${ }^{12}$ do herói parecia encerrado, uma nova produção chegou aos cinemas: RoboCop, dirigido por José Padilha e lançado comercialmente em 2014. Algo semelhante aconteceu com $O$ exterminador do futuro, de 1984. Em 1991, ele ganhou uma continuação: $O$ exterminador do futuro 2: o julgamento final. Mais um componente foi adicionado à série em 2003, com $O$ exterminador do futuro 3: a rebeliāo das máquinas, e, em 2009, foi lançado $O$ exterminador do futuro 4: a salvação. A série Aliens, que já contava com quatro filmes próprios e dois crossovers com a franquia Predador, beirava a exaustão do tema e ganhou, por sua vez, um prequel (uma produção posterior que narra eventos cronologicamente anteriores à obra original) com Prometheus, de 2012.

Não são casos isolados. Encontraremos, dentre os lançamentos mais recentes, uma multiplicidade de remakes, reboots, prequels e continuaçôes (desdobramentos que eventualmente expandem as histórias, acrescentando novos conteúdos e oferecendo possibilidades de leitura ainda não exploradas). Essa estratégia, entretanto, pode ser traiçoeira: existe um limite de saturação a partir do qual, em vez de enriquecer seu tesouro narrativo, a indústria cinematográfica nada mais faz do que recontar a mesma história mais uma e outra vez. $\mathrm{O}$ apelo

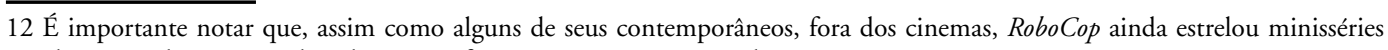
televisivas, alguns jogos de videogame e fez aparições em outras mídias. 
sistemático a fórmulas fatigadas, embora comercialmente interessante ao negócio hollywoodiano, não deixa de ser uma versão particular do autômaton, o que faznos questionar: ao mesmo tempo em que consegue enunciar, através da ficção, a condição maquínica do sujeito contemporâneo, não padece o cinema do próprio sintoma que desvela? E, partindo do princípio de que o propósito da ficção é precisamente provocar a imaginação, esse retorno incansável e potencialmente estéril a esquemas repetitivos não culminaria na traição de sua função original? 


\section{REFERÊNCIAS}

Abraham, M., Newman, E. (Produção) \& Padilha, J. (Direção). (2014). Robocop. [Filme cinematográfico]. Los Angeles: Metro-Goldwyn-Mayer Pictures, Columbia Pictures.

Andersen, H. C. (2000). O rouxinol e o imperador da China. São Paulo: Global. Anderson, D., Borman, M., Kubicek, V. \& Silver, J. (Produção) \& McG (Direção). O exterminador do futuro 4: a salvação. [Filme cinematográfico]. Los Angeles: Warner Bros e Columbia Pictures.

Arendt, H. (2007). A condição humana. R. Raposo (Trad., 10a ed.). Rio de Janeiro: Forense Universitária.

Asimov, I. (2010). Os robôs, os computadores e o medo. In I. Asimov. Histórias de robô (Vol. 2, pp. 7-18). Porto Alegre: L\&PM.

Benjamin, W. (2010). Experiência e pobreza. In W. Benjamin. Magia e técnica, arte e politica. (7a ed., p. 114-119). São Paulo: Brasiliense.

Blaustein, J. (Produção) \& Wise, R. (Direção). (1951). O dia em que a Terra parou. [Filme cinematográfico]. Los Angeles: 20th Century Fox.

Borges, J. L. (1974). El golem. In J. L. Borges. Obras completas. (pp. 885-887). Buenos Aires: Emecé.

Bruce, J. D. (1913, April). Automata in classical tradition and mediaeval romance. Modern Philology, 10(4), 511-526.

Bueno, Y. M. B. \& Martins, R. N. (2012). A trajetória persistente do autômato na literatura e no cinema de ficção. In Anais s 35 Congresso Brasileiro de Ciências da Comunicação. (pp. 1-14), Fortaleza. São Paulo: Intercom. Recuperado a partir de http://www.intercom.org.br/sis/2012/resumos/R7-1437-1.pdf

Cameron, J. (Produção \& Direção). (1991). O exterminador do futuro 2: o julgamento final. [Filme cinematográfico]. Los Angeles: Tristar Pictures.

Carroll, G., Giler, D., Hill, W., (Produção) \& Scott, R. (Direção). (1979). Alien: o oitavo passageiro. [Filme cinematográfico]. Los Angeles, Londres: Columbia Pictures.

Cavarero, A. \& Butler, J. (2007, setembro-dezembro). Condição humana contra "natureza". Estudos Feministas, 15(3), 650-662. 
Crowley, P. (Produção) \& Dekker, F. (Direção). (1993). Robocop 3. [Filme cinematográfico]. Los Angeles: Orion Pictures.

Dahmer, A. (2009). Monumento a um jovem monólito. In Malvados [blog]. Recuperado a partir de http://betobertagna.com/2010/08/24/monumento-aum-jovem-monolito-via-blog-dos-malvados/

Davidson, P. (Produção), Boese, C. \& Wegener, P. (Direção). (1920). Der Golem, wie er in die Welt kam. [Filme cinematográfico]. Alemanha: Projektions-AG Union (PAGU).

Davidson, P. (Produção), Gliese, R. \& Wegener, P. (Direção). (1917). Der Golem und die Tänzerin. [Filme cinematográfico]. Alemanha: Deutsche Bioscop $\mathrm{GmbH}$.

Davidson, P. (Produção) \& Lubitsch, E. (1919). Die Puppe. [Filme cinematográfico]. Alemanha: Projektions-AG Union (PAGU).

Davison, J. (Produção) \& Kershner, I. (Direção). (1990). Robocop 2. [Filme cinematográfico]. Los Angeles: Orion Pictures.

Dawley, J. S. (Produção \& Direção). (1910). Frankenstein. [Filme cinematográfico]. Estados Unidos: Edison Manufacturing Company.

Deeley, M. (Produção) \& Scott, R. (Direção). (1982). Blade Runner. [Filme cinematográfico]. Los Angeles: Warner Bros.

Donner, L. S., Kinberg, S., Parker, H. (Produção) \& Singer, B. (Produção e Direção). (2014). X-Men: dias de um futuro esquecido. [Filme cinematográfico]. Los Angeles: 20th Century Fox.

Ellison, M., Landay, V. (Produção) \& Jonze, S. (Produção e Direção). (2013). Ela. [Filme cinematográfico]. Los Angeles: Warner Bros.

Freud, S. (1919). O estranho. In J. Salomão (Trad.), Edição standard brasileira das obras psicológicas completas de Sigmund Freud (Vol. 17, pp. 233-273). Rio de Janeiro: Imago, 2006. (Publicado originalmente em 1919).

Freud, S. (1920). Além do princípio do prazer. In J. Salomão (Trad.), Edição standard brasileira das obras psicológicas completas de Sigmund Freud (Vol. 18, pp. 11-75). Rio de Janeiro: Imago, 2006. (Publicado originalmente em 1920). 
Freud, S. (1930). Mal-estar na civilização. In J. Salomão (Trad.), Edição standard brasileira das obras psicológicas completas de Sigmund Freud (Vol. 21, pp. 65148). Rio de Janeiro: Imago, 2006. (Publicado originalmente em 1930).

Galenn, H. \& Wegener, P. (Produção e Direção). (1915). Der Golem. [Filme cinematográfico]. Alemanha: Deutsche Bioscop GmbH.

Giler, D., Hill, W. (Produção) \& Scott, R. (Produção e Direção). (2012). Prometheus. [Filme cinematográfico]. Los Angeles, Londres: 20th Century Fox.

Goethe, Pandora. (2003). O ensaio como forma. In T. W. Adorno. Notas de Literatura I. J. de Almeida, (Trad., pp. 15-45). Rio de Janeiro: Editora 34.

Hurd, G. A. (Produção) \& Cameron, J. (Direção). (1984). O exterminador do futuro. [Filme cinematográfico]. Los Angeles: Orion Pictures.

Hyde, W. W. (1913, October). Note on human automata. Modern Philology, 11(2), 267-268.

Jerusalinsky, A. (2011). Gotinhas e comprimidos para crianças sem história: uma psicopatologia pós-moderna para a infância. In A. Jerusalinky \& S. Fendrik (Orgs.), O livro negro da psicopatologia contemporânea. (2a ed., pp. 231-242). São Paulo: Via Lettera.

Kassar, M., Vajna, A. G., Michaels, J. B., Lieberman, H., Wilson, C., (Produção) \& Mostow, J. (Direção). (2003). O exterminador do futuro 3: a rebeliāo das máquinas. [Filme cinematográfico]. Los Angeles: Warner Bros, Columbia Pictures.

Kennedy, K., Curtis, B. (Produção) \& Spielberg, S. (Produção e Direção). (2001). A. I.: inteligência artificial. [Filme cinematográfico]. Los Angeles: Warner Bros, DreamWorks.

King, G., Headington, T., Depp, J. (Produção) \& Scorcese, F. (Produção \& Direção) (2011). A invenção de Hugo Cabret. [Filme cinematográfico]. Estados Unidos, Reino Unido, França: Paramount Pictures, Entertainment Film Distributors.

Kobritz, R., Franco, L. J. (Produção) \& Carpenter, J. (Direção). (1983). Christine, o carro assassino. [Filme cinematográfico]. Los Angeles: Columbia Pictures.

Kubrick, S. (Produção e Direção). (1968). 2001: uma odisseia no espaço. [Filme cinematográfico]. Los Angeles: Metro-Goldwyn-Mayer. 
Kurtz, G. (Produção) \& Lucas, G. (Direção). (1977). Guerra nas estrelas: episódio IV: uma nova esperança. [Filme cinematográfico]. Los Angeles: 20th Century Fox.

Lacan, J. (1953-1954). O seminário, Livro 1: os escritos técnicos de Freud (3a ed.). Rio de Janeiro: Jorge Zahar, 1986. (Publicado originalmente em 1953-1954).

Lacan, J. (1955-1956). O seminário, Livro 3: as psicoses. Rio de Janeiro: Jorge Zahar, 2010. (Publicado originalmente em 1955-1956).

Lacan, J. (1964). O seminário, Livro 11: os quatro conceitos fundamentais da psicanálise. Rio de Janeiro: Jorge Zahar, 2008. (Publicado originalmente em 1964).

Lang, F. (Produção \& Direção). (1927). Metrópolis. [Filme cinematográfico]. Alemanha: Universum Film (UFA).

LeRoy, M. (Produção) \& Fleming, V. (Direção). (1939). O mágico de Oz. [Filme cinematográfico]. Los Angeles: Metro-Goldwyn-Mayer.

Lippmann, H. (Produção) \& Ripert, O. (Direção). (1916). Homunculus, 1. Teil. [Filme cinematográfico]. Alemanha: Deutsche Bioscop GmbH.

Mark, L., Davis, J., Dow, T., Godfrey, W., (Produção) \& Proyas, A. (Direção). (2004). Eu, robô. [Filme cinematográfico]. Los Angeles: 20th Century Fox.

Mattuela, L. A. (2012). Todos são felizes agora: a ficção literária como interpretação da cultura. In R. T. de Souza (Org.), Literatura e psicanálise: encontros contemporâneos. (pp. 262-275). Porto Alegre: Dublinense.

McCallum, R. (Produção) \& Lucas, G. (Produção \& Direção). (2001). Guerra nas estrelas: episódio I: a ameaça fantasma. [Filme cinematográfico]. Los Angeles: 20th Century Fox.

Méliès, G. (Produção e Direção). (1897). Gugusse et L'Automate. [Filme cinematográfico]. França: Star Film.

Méliès, G. (Produção e Direção). (1908). Poupée vivante. [Filme cinematográfico]. França: Star Film.

Nayfack, N. (Produção) \& Wilcox, F. M. (Direção). (1956). Planeta proibido. [Filme cinematográfico]. Los Angeles: Metro-Goldwyn-Mayer. 
Nuñez, C. F. P. (2008). A dimensão tecnomística dos autómata (prodígios técnicos) e émpsykha agálmata (criaturas animadas) no imaginário da Grécia antiga. Principia, 16. Recuperado a partir de http://www.e-publicacoes.uerj. br/index.php/principia/article/view/11216

Oliveira Neto, J. M. (2010, setembro). A ficção científica, os robôs e a Modernidade: segunda parte. Revista Blecaute, 6, 16-23.

Petersen, W., Katz, G., Mark, L., Miller, N., Radcliffe, M., Barnathan, M., (Produção) \& Columbus (Produção e Direção). (1999). O homem bicentenário. [Filme cinematográfico]. Estados Unidos, Canadá: Buena Vista Pictures.

Phillips, J., Phillips, M. (Produção) \& Spielberg, S. (Direção). (1977). Contatos imediatos de terceiro grau. [Filme cinematográfico]. Los Angeles: Columbia Pictures.

Quinet, A. (2010). Psicose e laço social. Rio de Janeiro: Jorge Zahar.

Schmidt, A. (Produção) \& Verhoeven, P. (Direção). (1987). Robocop. [Filme cinematográfico]. Los Angeles: Orion Pictures.

Schneer, C. H. (Produção) \& Chaffey, D. (Direção). (1963). Jasão e o velo de ouro. [Filme cinematográfico]. Estados Unidos, Reino Unido: Columbia Pictures.

Silver, J. (Produção), Wachowski, L. \& Wachowski, L. (Direção). (1999). Matrix. [Filme cinematográfico]. Estados Unidos, Austrália: Warner Bros. 